\title{
A Case of Hypothyroid Graves' Disease Following External Radiation Therapy to the Cervical Region
}

\author{
EIJUN NISHIHARA, SHUJI FUKATA, NOBUHIKO KIMURA*, MASAHIRO HAGIHARA, TAKUMI KUDO, \\ HIDEMI OHYE, MITSURU ITO, SUMIHISA KUBOTA, NOBUYUKI AMINO, KANJI KUMA AND AKIRA MIYAUCHI
}

Kuma Hospital, 8-2-35 Shimoyamate-dori, Chuo-ku, Kobe 650-0011, Japan

*Iwakuni Medical Center, 2-5-1 Kuroiso-machi, Iwakuni 740-8510, Japan

\begin{abstract}
A case of hypothyroid Graves' disease occurred following external radiation therapy to the cervical region is described. Severe hypothyroidism developed in a 56-year-old man 6 months after external radiation therapy for submandibular cancer. Serological evaluation of thyroid autoimmunity revealed the presence of antithyroid antibodies and thyrotropin-binding inhibitory immunogloblins (TBII). Diplopia, limitation of downward gaze, and palpebral edema developed 2 years after levothyroxine replacement therapy. Ocular magnetic resonance imaging revealed marked hypertrophy of the bilateral extraocular muscles with signal hyperintensity on T2-weighted images. This infiltrative ophthalmopathy showed marked improvement after additional treatment with high-dose methylprednisolone and orbital radiation, in parallel with a decrease in TBII. These results suggest that radiation-associated thyroidal injury might be associated with the etiology of hypothyroid Graves' disease.
\end{abstract}

Key words: Hypothyroid Graves' disease, External radiation therapy, Graves' ophthalmopathy, TBII, TSAb

(Endocrine Journal 53: 357-361, 2006)

THYROID dysfunction is common in patients who have undergone therapeutic external radiation to the cervical region $[1,2]$. Primary hypothyroidism is the most common radiation-induced thyroid dysfunction, accounting for $20 \%$ to $30 \%$ of cases, with approximately half of the cases presenting within 5 years after treatment [2]. The risk of thyroid cancer in these patients is 15 times as high as that in a nonirradiated population [1,2]. In addition, Graves' disease, Graves' ophthalmopathy or both may develop after external radiation therapy, with a prevalence of $0.1 \%$ to $7 \%$, in patients treated for Hodgkin's disease [3-6].

Hypothyroid Graves' disease is rare and is defined as a subgroup of Graves' disease, based on the presence of Graves' ophthalmopathy and hypothyroidism without a history of antithyroid treatment [7]. Serological evaluation for thyroid autoimmunity also indicates that

Received: December 21, 2005

Accepted: February 28, 2006

Correspondence to: Eijun NISHIHARA, M.D., Ph.D., Kuma Hospital, 8-2-35 Shimoyamate-dori, Chuo-ku, Kobe 650-0011, Japan thyroid-stimulation blocking antibodies (TSBAb) are not a cause of hypothyroidism, but that destructive changes in the thyroid are probably responsible for hypothyroidism [8]. In contrast, thyroid-stimulating antibodies (TSAb) are detected in most patients with hypothyroid Graves' disease [8]. Although the exact etiology of the ophthalmopathy in hypothyroid Graves' disease remains controversial, the severity of Graves' ophthalmopathy is correlated with TSAb titers [9].

Here, we report on a case of severe hypothyroid Graves' disease which developed after external radiotherapy to the cervical region.

\section{Case Report}

A 56-year-old male noticed a right cervical node enlargement in May 2001. Extensive resection of the primary tumor and neck dissection were performed at a local hospital. Subsequent pathological studies showed squamous cell carcinoma of the submandibular gland with metastasis to the cervical lymph nodes. 


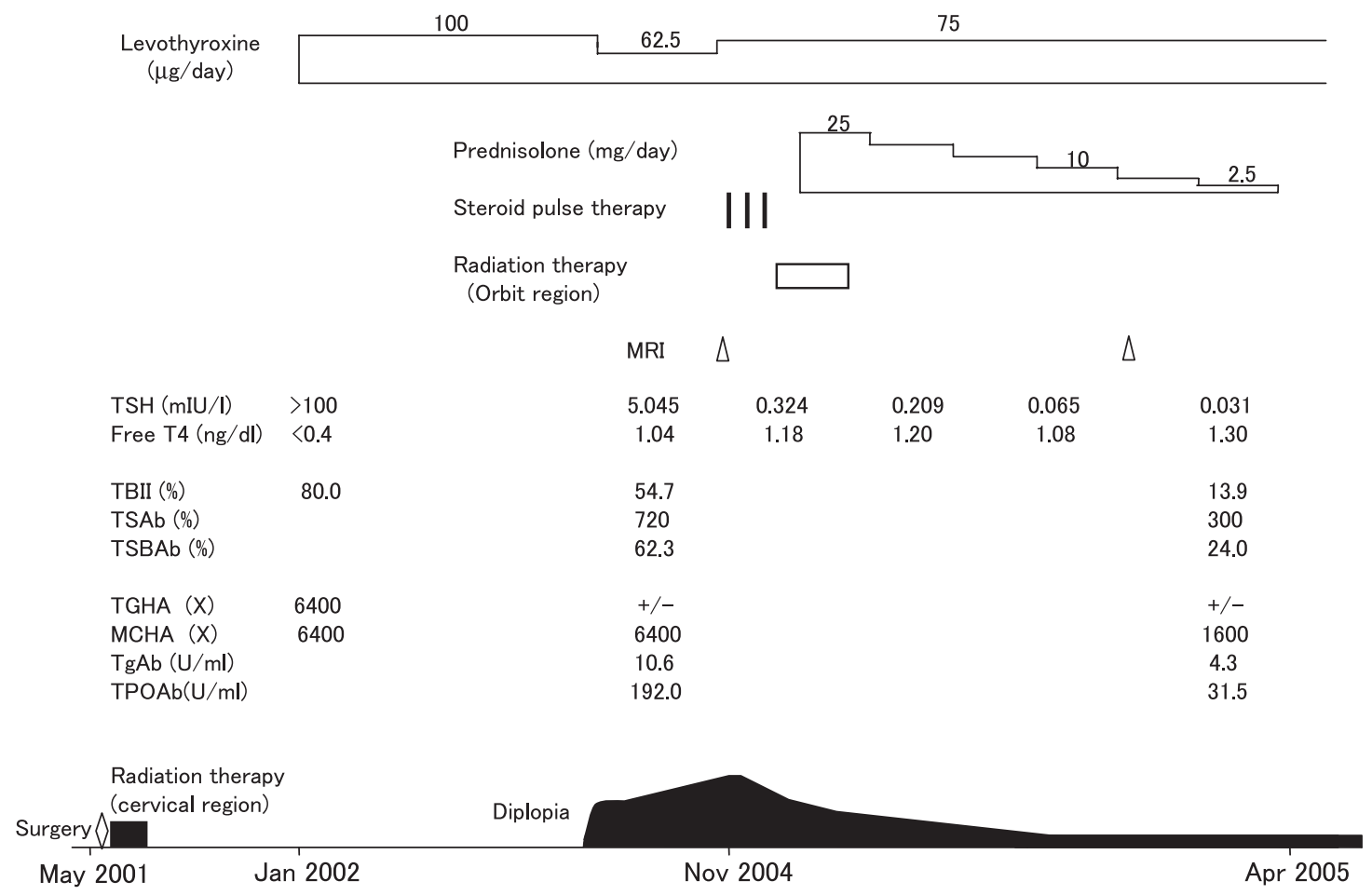

Fig. 1. Thyroid function tests and immunological findings during the clinical course.

After surgery, the patient received external radiation therapy, with 60 Gy delivered in 30 fractions over 6 weeks to the right submandibular region and the right cervical region, including the thyroid gland. Marked generalized fatigue and pretibial edema developed 2 months before hypothyroidism was diagnosed in January 2002 (Fig. 1). Treatment with $100 \mu \mathrm{g} /$ day levothyroxine was started to establish and maintain a euthyroid status. In January 2004, several eye symptoms, including diplopia, limitation of downward gaze, and palpebral edema, developed and gradually worsened, 10 months before the patient consulted our hospital.

The patient was $170 \mathrm{~cm}$ tall and weighted $55 \mathrm{~kg}$. The family history was negative for thyroid diseases. Physical examination revealed limitations of upward, downward and lateral gazes, and proptosis $(23 \mathrm{~mm}$ for the right eye and $22 \mathrm{~mm}$ for the left eye on the exophthalmometry). The thyroid gland was not palpable, and thyroid ultrasonography revealed diffuse hypoechogenicity and normal thyroid volume of $12.8 \mathrm{ml}$, which was estimated by using the equation for an ellipsoid: pi/6 (length $\times$ height $\times$ width). Thyrotropin $(\mathrm{TSH})$ and free thyroxine (FT4) concentrations were measured by enzyme immunoassays (AxSYM TSH and AxSYM
FT4, respectively, Abbott Japan Co., Tokyo, Japan). The reference ranges used for serum TSH and FT4 were $0.30-5.00 \mathrm{mIU} / 1$ and $0.70-1.60 \mathrm{ng} / \mathrm{dl}$, respectively. TBII activity was measured with the commercial ELISA kit (RSR Ltd., Cardiff, UK, normal range less than $15 \%)$. TSAb and TSBAb were measured by the commercial RIA assay kits (Yamasa Co., Chiba, Japan, normal range less than $180 \%$ and less than $45.6 \%$, respectively). Anti-thyroglobulin and anti-thyroid microsomal antibodies were determined by commercially available hemagglutination methods (TGHA: Thyroid test and MCHA: Microsome test, Fuji Rebio Inc., Tokyo, Japan, normal ranges less than 100, respectively). Anti-thyroglobulin antibodies ( $\mathrm{TgAb}$ ) and antithyroid peroxidase antibodies (TPOAb) were measured with a commercial RIA kit (RSR Ltd., Cardiff, UK, normal range less than $0.3 \mathrm{U} / \mathrm{ml}$, respectively). Laboratory studies revealed that a near-euthyroid state had been achieved with levothyroxine replacement therapy (62.5 $\mu \mathrm{g}$ /day). TBII and TSAb, and anti-thyroid antibodies (TgAb and TPOAb), were positive (Fig. 1). Ocular magnetic resonance (MR) revealed marked hypertrophy of the bilateral extraocular muscles with signal hyperintensity on T2-weighted images (Fig. 2A, B). Treatment with methylprednisolone, $1000 \mathrm{mg}$ per day 

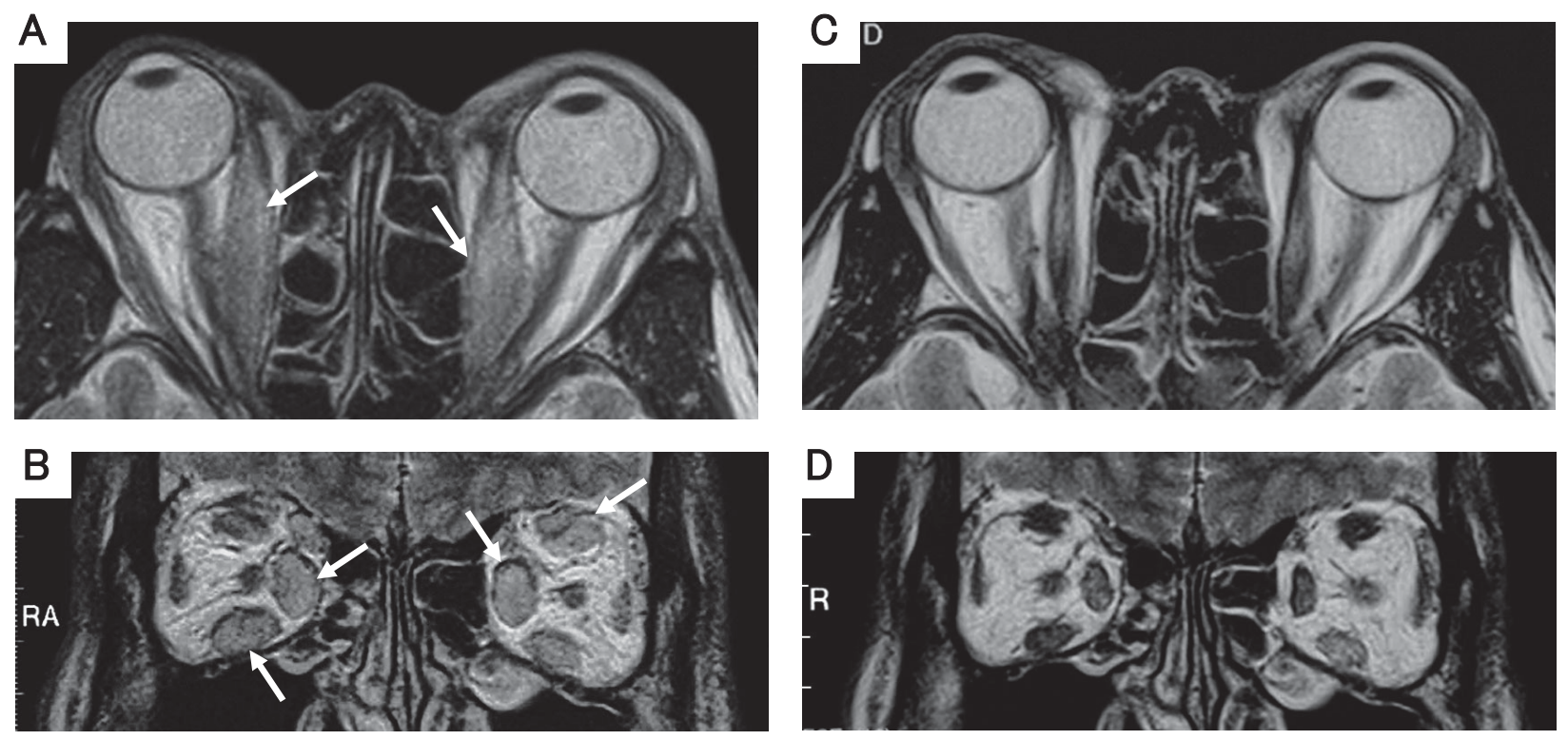

Fig. 2. Ocular MR (T2-weighted images)

Arrows indicate enlarged extraocular muscles with signal hyperintensity on T2-weighted images.

for 3 days/week, was performed over a 3-week period and was followed by radiation to the orbit, with $20 \mathrm{~Gy}$ delivered in 10 fractions over 2 weeks. Thereafter, prednisolone was administered orally $(20 \mathrm{mg} /$ day $)$ and tapered. Visual symptoms showed marked improvement, which was in the accordance with the improvement in muscle hypertrophy and the disappearance of signal hyperintensity on T2-weighted MR images (Fig. 2C, D). When prednisolone was withdrawn (Fig. 1), immunoactivity for TBII, TSAb, TgAb, and TPOAb also decreased to $13.9 \%, 300 \%, 4.3 \mathrm{U} / \mathrm{ml}$, and $31.5 \mathrm{U} /$ $\mathrm{ml}$, respectively. Mild diplopia remained, but the limitation of gaze and the palpebral edema were clearly improved. The patient showed no other sign or symptom suggesting recurrence of ophthalmopathy 6 months after high-dose methylprednisolone treatment and radiation therapy to the orbit.

\section{Discussion}

Since Fox and Schwartz reported on 46 patients with hypothyroid Graves' disease in 1967 [10], no susceptibility gene or environmental factors have been reported to be associated with the onset of this disease. External radiation significantly increases incidences of both hypothyroidism [2] and Graves' ophthalmopathy [2-4] in patients exposed therapeutic doses (30-70 Gy) to the cervical region. These evidences suggest that onset of hypothyroidism and/or Graves' ophthalmopathy in the present case might be triggered by thyroidal injury with external radiation therapy. In a review of the literature from 1967 through 2004 found 6 cases of hypothyroidism and ophthalmopathy during radiation therapy [1113, 4] (Table 1). Although 4 cases were poorly documented, clinical features of ophthalmopathy in 2 cases were improved by treatment with prednisolone and levothyroxine and with retro-orbital radiation therapy, respectively [11, 12]. Antithyroid antibodies were positive in 3 cases, but TBII was not detected in any cases. Furthermore, all patients had Hodgkin's or nonHodgkin's lymphoma. Thyroid dysfunction observed in malignant lymphoma survivors can be caused in part by immune regulation disorders [6], suggesting that thyroid dysfunction might occur even if these patients did not receive cervical radiation therapy.

The age of our present patient, the radiation dose, and the latency until the onset of hypothyroidism or Graves' ophthalmopathy were similar to those previously reported cases, although the underlying disease in the present case was uniquely submandibular cancer (Table 1). Moreover, at the onset of severe hypothyroidism 6 months after external radiation therapy to the cervical region, TBII and TSAb were positive, in agreement with a previous report of autoantibodies in hypothyroid Graves' disease [8]. Although several 
Table 1. Ophthalmopathy and primary hypothyroidism without prior hyperthyroidism after external radiation therapy

\begin{tabular}{|c|c|c|c|c|c|c|c|c|c|c|}
\hline \multirow{2}{*}{$\begin{array}{l}\text { Number of } \\
\text { Patients }\end{array}$} & \multirow{2}{*}{ Age } & \multirow{2}{*}{ Sex } & \multirow{2}{*}{$\begin{array}{l}\text { Radiation } \\
\text { Dose (Gy) }\end{array}$} & \multicolumn{2}{|c|}{ Latency period (years) } & \multirow{2}{*}{ TBII } & \multirow{2}{*}{$\begin{array}{l}\text { Anti- } \\
\text { microsomal } \\
\text { Antibody }\end{array}$} & \multirow{2}{*}{$\begin{array}{l}\text { Anti- } \\
\text { thyroglobulin } \\
\text { Antibody }\end{array}$} & \multirow{2}{*}{$\begin{array}{l}\text { Underlying } \\
\text { Disease }\end{array}$} & \multirow{2}{*}{ Reference } \\
\hline & & & & Hypothyroid & Ophthalmopathy & & & & & \\
\hline 1 & 60 & $\mathrm{~F}$ & 55 & 0.3 & 2.5 & - & + & + & $\begin{array}{l}\text { Non-Hodgkin's } \\
\text { lymphoma }\end{array}$ & (11) \\
\hline 1 & 63 & $\mathrm{~F}$ & 54 & 10 & 10 & - & + & + & $\begin{array}{l}\text { Hodgkin's } \\
\text { disease }\end{array}$ & (12) \\
\hline 1 & NR & M & NR & NR & NR & NR & + & + & $\begin{array}{l}\text { Hodgkin's } \\
\text { disease }\end{array}$ & (13) \\
\hline 3 & NR & NR & NR & NR & NR & NR & NR & NR & $\begin{array}{l}\text { Hodgkin's } \\
\text { disease }\end{array}$ & (4) \\
\hline 1 & 56 & M & 60 & 0.5 & 2.5 & + & + & + & $\begin{array}{l}\text { Submandibular } \\
\text { cancer }\end{array}$ & $\begin{array}{l}\text { present } \\
\text { case }\end{array}$ \\
\hline
\end{tabular}

NR, not reported

reports suggest that the ophthalmopathy in cases of hypothyroid Graves' disease improves spontaneously during levothyroxine replacement therapy [14, 15], in our patient treatment with levothyroxine that achieved a euthyroid state could not prevent ophthalmopathy 2 years later. However, the improvement in infiltrative ophthalmopathy and the decrease in TBII can be attributed to the additional treatment with high-dose methylprednisolone and orbital radiation.

A possible mechanism of radiotherapy-induced thyroid dysfunction involves direct thyroid cell injury from radiation and immunological reactions induced by the release of autoantigens or by $\mathrm{T}$ helper lymphocyte overbalance $[1,2]$. The frequency of autoimmune thyroid diseases, including Hashimoto's thyroiditis $[16,17]$, Graves' disease [3-6] and Graves' ophthalmopathy [4], in patients who have received external radiation therapy is significantly higher than that in untreated controls. Indeed, patients who have received external radiation to the cervical region are more likely to have antithyroid antibodies than are untreated patients [17], and the titers of antithyroid antibodies are elevated after radiation therapy [18]. In our case, various autoimmune antibodies, including TSAb, TgAb and TPOAb, were detected at the onset of Graves' ophthalmopathy. Since the accurate measurement of
TSBAb activities depends on low concentrations of TSAb [8], TSBAb is out of evaluation at the onset of Graves' ophthalmopathy. According to previous reports, titers of TSAb, but not of TBII, are significantly higher in patients with Graves' ophthalmopathy than in patients without Graves' ophthalmopathy [19], and the severity of Graves' ophthalmopathy is correlated with TSAb titers [9]. Although the absence of TPOAb is associated with a 5-fold increased risk of Graves' ophthalmopathy, the presence of TPOAb or $\mathrm{TgAb}$ is not a risk factor for Graves' ophthalmopathy [20]. These findings suggest that of the autoimmune antibodies detected in this case, TSAb is the most likely to be related to the development of Graves' ophthalmopathy.

We have reported what we believe is the first known case of hypothyroid Graves' disease with positive TSH receptor antibodies, triggered by external radiation to the neck. For curative treatment of nonthyroidal neoplastic diseases in the cervical region, external radiation therapy is extremely popular and sometimes cannot avoid including the thyroid gland within the field. Therefore, occurrence of severe hypothyroid Graves' disease should be paid attention to during follow-up of patients who have received external radiation therapy to the cervical region.

\section{References}

1. Hancock SL, McDougall IR, Constine LS (1995) Thyroid abnormalities after therapeutic external radiation. Int J Radiat Oncol Biol Phys 31: 1165-1170.

2. Jereczek-Fossa BA, Alterio D, Jassem J, Gibelli B, Tradati N, Orecchia R (2004) Radiotherapy-induced thyroid disorders. Cancer Treat Rev 30: 369-384.

3. Mortimer RH, Hill GE, Galligan JP, Bransden AI, Tyack SA, Roeser HP (1986) Hypothyroidism and Graves' disease after mantle irradiation: a follow up study. Aus N Z J Med 16: 347-351. 
4. Hancock SL, Cox RS, McDougall IR (1991) Thyroid diseases after treatment of Hodgkin's disease. $N$ Engl J Med 325: 599-605.

5. Thomas O, Mahe M, Campion L, Bourdin S, Milpied N, Brunet G, Lisbona A, Le Mevel A, Moreau P, Harousseau J, Cuilliere J (2001) Long-term complications of total body irradiation in adults. Int $J$ Radiat Oncol Biol Phys 49: 125-131.

6. Illes A, Biro E, Miltenyi Z, Keresztes K, Varoczy L, Andras C, Sipka S, Bako G (2003) Hypothyroidism and thyroiditis after therapy for Hodgkin's disease. Acta Haematol 109: 11-17.

7. Christy JH, Morse RS (1977) Hypothyroid Graves' disease. Am J Med 62: 291-296.

8. Kasagi K, Hidaka A, Nakamura H, Takeuchi R, Misaki T, Iida Y, Konishi J (1993) Thyrotropin receptor antibodies in hypothyroid Graves' disease. J Clin Endocrinol Metab 76: 504-508.

9. Noh JY, Hamada N, Inoue Y, Abe Y, Ito K (2000) Thyroid-stimulating antibody is related to Graves' ophthalmopathy, but thyrotropin-binding inhibitor immunoglobulin is related to hyperthyroidism in patients with Graves' disease. Thyroid 10: 809-813.

10. Fox RA, Schwartz TB (1967) Infiltrative ophthalmopathy and primary hypothyroidism. Ann Intern Med 67: $377-380$.

11. Wasnich RD, Grumet FC, Payne RO, Kriss JP (1973) Graves' ophthalmopathy following external neck irradiation for nonthyroidal neoplastic disease. J Clin Endocrinol Metab 37: 703-713.

12. Jackson R, Rosenberg C, Kleinmann R, Vagenakis AG, Braverman LE (1979) Ophthalmopathy after neck irradiation therapy for Hodgkin's disease. Cancer Treat Rep 63: 1393-1395.

13. Schimpff SC, Diggs CH, Wiswell JG, Salvatore PC, Wiernik PH (1980) Radiation-related thyroid dysfunction: implications for the treatment of Hodgkin's disease. Ann Intern Med 92: 91-98.

14. Tamaki H, Amino N, Iwatani Y, Miyai K (1989) Im- provement of infiltrative ophthalmopathy in parallel with decrease of thyroid-stimulating antibody (TSAb) activity in two patients with hypothyroid Graves' disease. J Endocrinol Invest 12: 47-53.

15. Nakai M, Okada Y, Tanikawa T, Kanda K, Morita E, Tanaka Y (2003) A case of Hypothyroid Graves' disease with extremely high titers of TSAb. J Uoeh 25 333-339.

16. Markson JL, Flatman GE (1965) Myxoedema after deep X-ray therapy to the neck. Br Med J 5444: 12281230 .

17. Tamura K, Shimaoka K, Friedman M (1981) Thyroid abnormalities associated with treatment of malignant lymphoma. Cancer 47: 2704-2711.

18. Sinard RJ, Tobin EJ, Mazzaferri EL, Hodgson SE, Young DC, Kunz AL, Malhotra PS, Fritz MA, Schuller DE (2000) Hypothyroidism after treatment for nonthyroid head and neck cancer. Arch Otolaryngol Head Neck Surg 126: 652-657.

19. Nishikawa M, Yoshimura M, Toyoda N, Masaki H, Yonemoto T, Gondou A, Kato T, Kurokawa H, Furumura T, Inada M (1993) Correlation of orbital muscle changes evaluated by magnetic resonance imaging and thyroid-stimulating antibody in patients with Graves' ophthalmopathy. Acta Endocrinol (Copenh) 129: 213-219.

20. Khoo DH, Ho SC, Seah LL, Fong KS, Tai ES, Chee SP, Eng PH, Aw SE, Fok AC (1999) The combination of absent thyroid peroxidase antibodies and high thyroid-stimulating immunoglobulin levels in Graves' disease identifies a group at markedly increased risk of ophthalmopathy. Thyroid 9: 1175-1180.

21. Tamai H, Kasagi K, Takaichi Y, Takamatsu J, Komaki G, Matsubayashi S, Konishi J, Kuma K, Kumagai LF, Nagataki S (1989) Development of spontaneous hypothyroidism in patients with Graves' disease treated with antithyroidal drugs: clinical, immunological, and histological findings in 26 patients. $J$ Clin Endocrinol Metab 69: 49-53. 